\title{
Does clofazimine have a prophylactic role against neuritis?
}

\author{
S. ARUNTHATHI \& KUMAR K. SATHEESH \\ Schieffelin Leprosy Research and Training Centre (SLR\&TC), Kari- \\ giri (PO) - 632 106, North Arcot Ambedkar District, Tamil Nadu, \\ India
}

Accepted for publication 17 February 1997

\begin{abstract}
Summary A study was undertaken with the aim of testing the usefulness of clofazimine as a prophylactic agent against neuritis and nerve damage. A modified regimen, using initial high doses of clofazimine followed by regular multibacillary multidrug therapy (MB-MDT) WHO regimen, was given to a series of consecutive cases of high risk borderline leprosy patients, fulfilling defined selection criteria $(n=65)$. These patients were studied for the incidence of neuritis/Type I reaction, over a period of 2 years. Results were compared with a matched series of consecutive cases treated only with regular MB-MDT WHO regimen $(n 1=57)$.

The difference in incidence rates of neuritis between the two groups was significant $(p<0 \cdot 01)$, suggesting that clofazimine may have a useful prophylactic role against neuritis/Type I reaction and nerve damage.
\end{abstract}

\section{Introduction}

Leprosy produces disability and deformity through nerve damage. Type I reactions (reversal reactions) are generally known to be a major cause of nerve damage in borderline leprosy (BL) patients. ${ }^{1}$ Prevention of deformity and disability is an integral part of leprosy control programmes, and they endeavour to achieve this through early detection and appropriate treatment of Type I reaction/neuritis. ${ }^{2}$

Reports of incidence rates of acute neuritis with or without associated inflammatory changes in the skin vary. ${ }^{2-4}$ However, it seems that the incidence of neuritis and Type I reaction is more among the multibacillary (MB) cases of the borderline spectrum, ${ }^{2,3}$ i.e. those cases of borderline-tuberculoid (BT), who are closer to the centre of the spectrum, midborderline leprosy (BB) and borderline lepromatous leprosy (BL). It is also known that the incidence of Type I reaction is more in the months immediately after the initiation of therapy - first 6 months for paucibacillary (PB) cases and first 12 months for MB cases., This seems especially so when the regimen includes rifampicin. ${ }^{3}$ Therefore, if an antiinflammatory drug with prophylactic activity against Type I reaction, can be used to cover those vulnerable first few months of MDT, ${ }^{6}$ especially in those who are at a higher risk for 
Type I reactions, perhaps the incidence rate of neuritis and consequent disability can be reduced.

Clofazimine is an effective antileprosy drug and its use in the treatment of Type II (ENL) reactions is well established. ${ }^{7}$ It is also known to have a prophylactic effect against episodes of Type II (ENL) reactions, once significantly high tissue levels are achieved. ${ }^{8,9}$ Though there were early reports of its use in Type I reactions, ${ }^{10}$ later reports found it to be of limited use, as it took 3-4 months to act and by then irretrievable nerve damage had occurred. ${ }^{11,12}$ There were also reports of clofazimine's probable modulating influence on Type I reaction when used along with steroids. ${ }^{13}$ However, no studies investigating the possible prophylactic action of clofazimine against Type I reaction have been reported.

The aim of this study is to explore the potential of clofazimine in a prophylactic role against Type I reaction/neuritis, in a selected group of high risk borderline leprosy patients.

\section{Patients and Methods}

All Borderline leprosy (BT, BT-BB, BL), ie.e excluding indeterminate, tuberculoid and lepromatous leprosy, patients attending the outpatient clinic at the Schieffelin Leprosy Research and Training Centre, Karigiri during the year 1988 and 1989 were considered for the study.

Patients were initially assessed clinically, their lesions charted, involved nerves identified, any functional defects recorded and skin smears taken. Patients were classified clinically using the Ridley \& Jopling classification and all except three (none of whom developed neuritis) had skin and nerve biopsies taken. Patients then underwent screening for tuberculosis and diabetes mellitus. Routine laboratory investigations including liver function tests and renal function tests were performed.

Type I reaction/neuritis was defined as an episode of acute inflammation in the nerves always accompanied by tenderness and often with pain in the affected nerves. Acute inflammatory changes in the skin lesions may also be present. From the population described above, patients who were estimated to be at a higher risk of Type I reaction/neuritis were termed as the high risk group.

The high risk group patients were selected as follows:

1 All cases of borderline lepromatous leprosy (BL). These patients had positive skin smears at routine sites. (The routine sites for Karigiri are right earlobe, left forehead, right chin, left buttock for male and left thigh for female and nasal scrapings from the mucosa over the anterior end of inferior turbinate.)

2 All cases grouped as BT-BB: ${ }^{14,15}$ These were borderline patients who were smear negative at routine sites, fulfilling the following criteria:

3 or more skin lesions;

3 or more nerves involved as evidenced by thickening and/or functional defect. (Lesions on the skin and the involved nerves must be well distributed.); and 'glove and stocking type of peripheral sensory impairment.

Two out of the above three criteria must be present for inclusion in this group (BT-BB).

BT-BB was a composite group consisting of cases who present clinically and on smear examinations as Paucibacillary leprosy. Most of these cases showed a picture of borderline lepromatous leprosy in the nerves and a picture of BT/Indeterminate histology in the skin biopsy. 
Patients falling into the above two groups (BL and BT-BB) constituted the high risk group.

Prophylactic potential of clofazimine was tested on these patients, subject to the following inclusion and exclusion criteria.

\section{Inclusion criteria}

All patients selected as the high risk group, as described above, formed the 'test group'.

All cases had received only dapsone monotherapy for less than 1-24 months prior to inclusion (Table 1).

\section{Exclusion Criteria}

Type I reaction/neuritis at the time of presentation.

Patients below the age of 16 years and above the age of 60 years.

Patients who had tuberculosis either diagnosed at the initial assessment or subsequently.

Patients who developed Type II (ENL) reaction, requiring increased dosages of clofazimine or steroids during therapy.

Hypersensitivity to any of the drugs used.

Female patients who were pregnant at the time of initial assessment.

The test group, thus selected was given the following initial regimen for 12 weeks: Cap. clofazimine $100 \mathrm{mg}$ tid; and Tab. dapsone $100 \mathrm{mg}$ od. The loading clofazimine dosage was $100 \mathrm{mg}$ tid in all cases except in those with a bodyweight of less than $40 \mathrm{~kg}$, for whom $100 \mathrm{mg}$ bid was given for the same duration. After completion of 12 weeks, patients were put on the standard MB-MDT WHO regimen. ${ }^{6}$

\section{CONTROLS}

Controls were chosen retrospectively for this clinical trial from the case registers of 1986 and 1987. All borderline cases were considered and the same inclusion and exclusion criteria were applied. All patients in this group were either newly diagnosed or had received dapsone monotherapy for less than 1-19 months (Table 1). All controls were directly put on standard MB-MDT WHO regimen.

All the patients were seen once monthly, when they were given the supervised doses, and

Table 1. Duration of dapsone monotherapy

\begin{tabular}{lcc}
\hline Duration of DDS (month) & Study Group & Control Group \\
\hline$<1$ & 6 & 12 \\
$2-5$ & 29 & 19 \\
$6-10$ & 12 & 7 \\
$11-24$ & 6 & 5 \\
No DDS & - & 3 \\
\hline Total & 53 & 46 \\
\hline
\end{tabular}


Table 2. Characteristics of the test group

\begin{tabular}{ll}
\hline Total no. of patients & 65 \\
Females & 21 \\
Males & 44 \\
Age & $18-56$ years \\
BT-BB & $38(58 \cdot 5 \%)$ \\
BL & $27(41 \cdot 5 \%)$ \\
Drop outs & $12(18.5 \%)$ \\
BT-BB & 6 \\
BL & 6 \\
\hline Total no. of patients & \\
who completed the study & $53(81 \cdot 5 \%)$ \\
\hline
\end{tabular}

examined carefully for the occurrence of Type I reaction/neuritis. Patients were also tested for any evidence of silent deterioration of nerve function by doing routine sensory and motor assessment. The maximum default period was 28 days, except for 4 patients among the test group and 6 patients among the control group, who had defaulted for periods ranging from 1 to 4 months during the course of their therapy. None of these patients give a history suggestive of Type I reaction/neuritis and their nerve status did not differ from previous records. All patients were followed up for a minimum period of 2 years.

\section{Results}

\section{TEST GROUP}

There was a total of 65 patients in the test group (Table 2), of whom 53 completed 24 pulses of MB-MDT after the initial 3 months of high dose clofazimine. These patients completed their therapy over a period ranging from 2 years and 4 months to 3 years and 1 month.

Drop outs were 12. Two patients dropped out between the 6th and 12th months of MB-MDT therapy, 7 patients between the 12th and 18th, and 3 patients between the 18 th and 24th months. None of these patients had recorded an episode of neuritis during the period they remained on treatment.

Incidence of neuritis/Type I reaction, during this period is shown in Table 3. Two patients developed Type I reaction with neural involvement as defined. One other patient developed

Table 3. Incidence of Type I reaction/neuritis in the test group

\begin{tabular}{ll} 
No. of patients who completed the study & 53 \\
Type I reaction/neuritis & 2 \\
Silent nerve paralysis & 1 \\
Total no. of patients with nerve damage & $3(5 \cdot 66 \%)$ \\
Incidence according to classification - BL & 2 \\
BT-BB & 1 \\
\hline
\end{tabular}


Table 4. Characteristics of the control group

\begin{tabular}{ll}
\hline Total no. of patients & 57 \\
Females & 10 \\
Males & 47 \\
Age & $18-60$ years \\
BT-BB & $39(68 \cdot 4 \%)$ \\
BL & $18(31 \cdot 6 \%)$ \\
Drop outs & $11(18 \cdot 5 \%)$ \\
BT-BB & 8 \\
BL & 3 \\
\hline $\begin{array}{l}\text { Total no. of patients } \\
\text { who completed the study }\end{array}$ & $46(81 \cdot 5 \%)$ \\
\hline
\end{tabular}

silent nerve paralysis, detected after the 20th pulse of MB-MDT. Thus a total of 3 patients $(5.66 \%)$ suffered nerve damage and were treated with steroids. Three others developed mild inflammation of the skin lesions without any neural involvement. They were treated with chloroquine and were not counted as neuritis/Type I reaction.

\section{CONTROLS}

There were a total of 57 patients in the control group (Table 4). Of these 46 completed 24 pulses of MB-MDT, over a period ranging from 2 years and 2 months to 2 years and 9 months. There were 11 drop outs. Seven patients dropped out before the completion of the first 6 months, 2 between the 6th and the 12th month, one between the 12th and the 18th month and one between the 18th and 24th month. One patient was diagnosed as having severe Type I reaction, with bilateral ulnar neuritis, just prior to dropping out. This case was included in the incidence rate for neuritis/Type I reaction.

The incidence rate of neuritis/Type I reaction in the control group is shown in Table 5. Twelve patients developed neuritis/Type I reaction as defined. One of them had a second episode after steroids were stopped. As this occurred within a month of stopping steroids, it was not clear whether it was a different episode or a continuation of the first. Therefore it was counted as one. One other patient developed inflammation of the skin lesions without neural involvement. He was treated with chloroquine and was not included in the incidence rate.

Table 5. Incidence of Type I reaction/neuritis in the control group

\begin{tabular}{ll}
\hline No. of patients who completed the study & 46 \\
Type I reaction/neuritis & $12(26 \cdot 1 \%)$ \\
Silent nerve paralysis & Nil \\
Total no. of patients with nerve damage & $12(26 \cdot 1 \%)$ \\
Incidence according to classification - BL & 7 \\
BT-BB & 5 \\
\hline
\end{tabular}


Table 6. Comparison of incidence rates; test vs controls

\begin{tabular}{lccc}
\hline & \multicolumn{3}{c}{ Type I Reaction/Neuritis } \\
\hline & Yes & No & Total \\
\hline Test Group & 3 & 50 & 53 \\
Control & 12 & 34 & 46 \\
\cline { 2 - 4 } & 15 & 84 & 99 \\
Total & & & \\
\hline & \\
$\chi^{2}$ (Corrected)* \\
$*$ Yates correction
\end{tabular}

The difference in incidence rates (Table 6) between the two groups was statistically significant $\left(P<0 \cdot 01 \cdot \chi^{2}\right.$ test $){ }^{*}$

\section{Discussion}

Clofazimine was chosen for this study after considering a number of factors. It has known anti-inflammatory $^{16-19}$ and immuno-modulatory properties. ${ }^{20,22}$ It has dose dependent increase in absorption $^{23}$ and cumulative retentive properties. ${ }^{24,25}$ It was reported that clofazimine was still detectable in the skin and the macrophages, two years after stopping therapy. ${ }^{26}$ Thus substantial tissue concentrations can be achieved and retained for a long

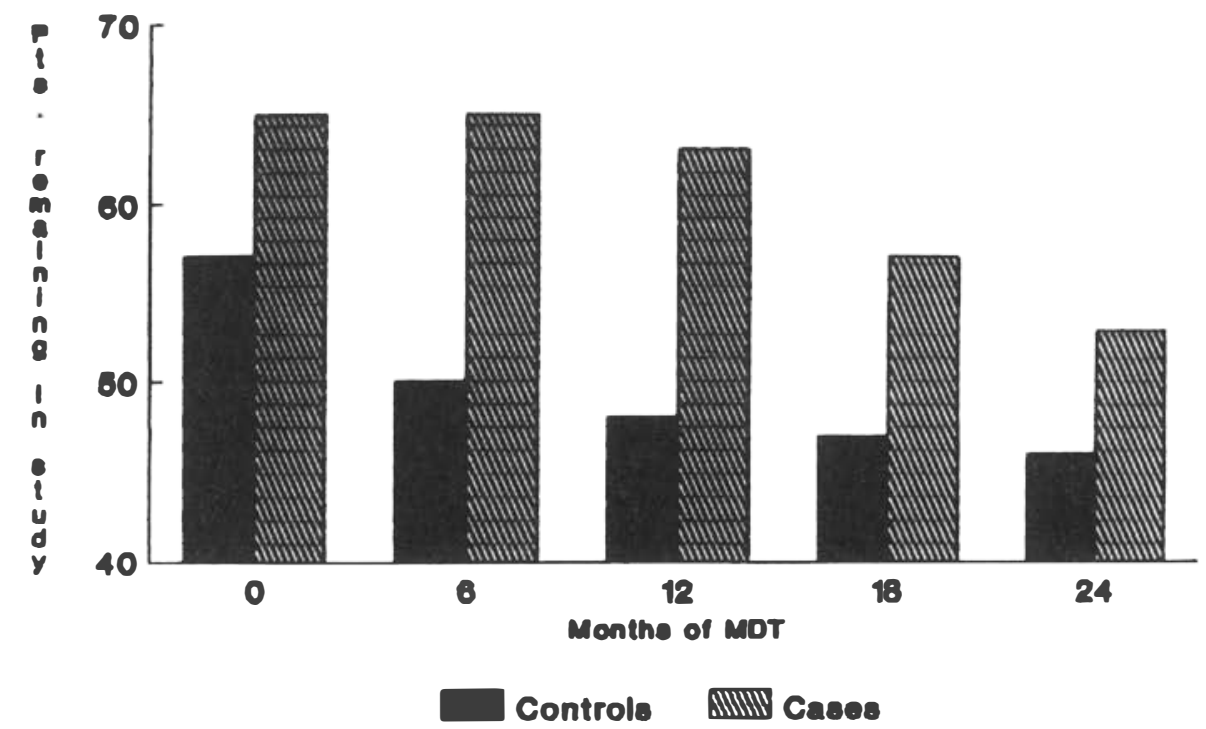

Figure 1. Pattern of drop outs. Comparison between the test group and the control group.

* None of the patients in the test group showed any significant side-effects to clofazimine, except discoloration. 
period, by an initial intensive therapy as was done in this study. From our personal experience and the reports of the others it appeared that clofazimine would help to halt the progress of neural involvement and at the same time avoid the hazards of prolonged steroid therapy. Thus it was thought worthwhile to seek a treatment regimen which would most effectively halt and positively reverse neural involvement in leprosy. ${ }^{10}$ Therapeutic prevention of the permanent neural sequel is usually not attained with conventional MDT. In many instances nerve involvement can be rapidly irreversible and can also be aggravated by conventional therapy.

Hence in this clinical study the trial regimen was designed in such a way as to achieve high tissue concentrations before the introduction of rifampicin as part of the standard MB-MDT WHO regimen. Low doses of clofazimine administered as part of the standard
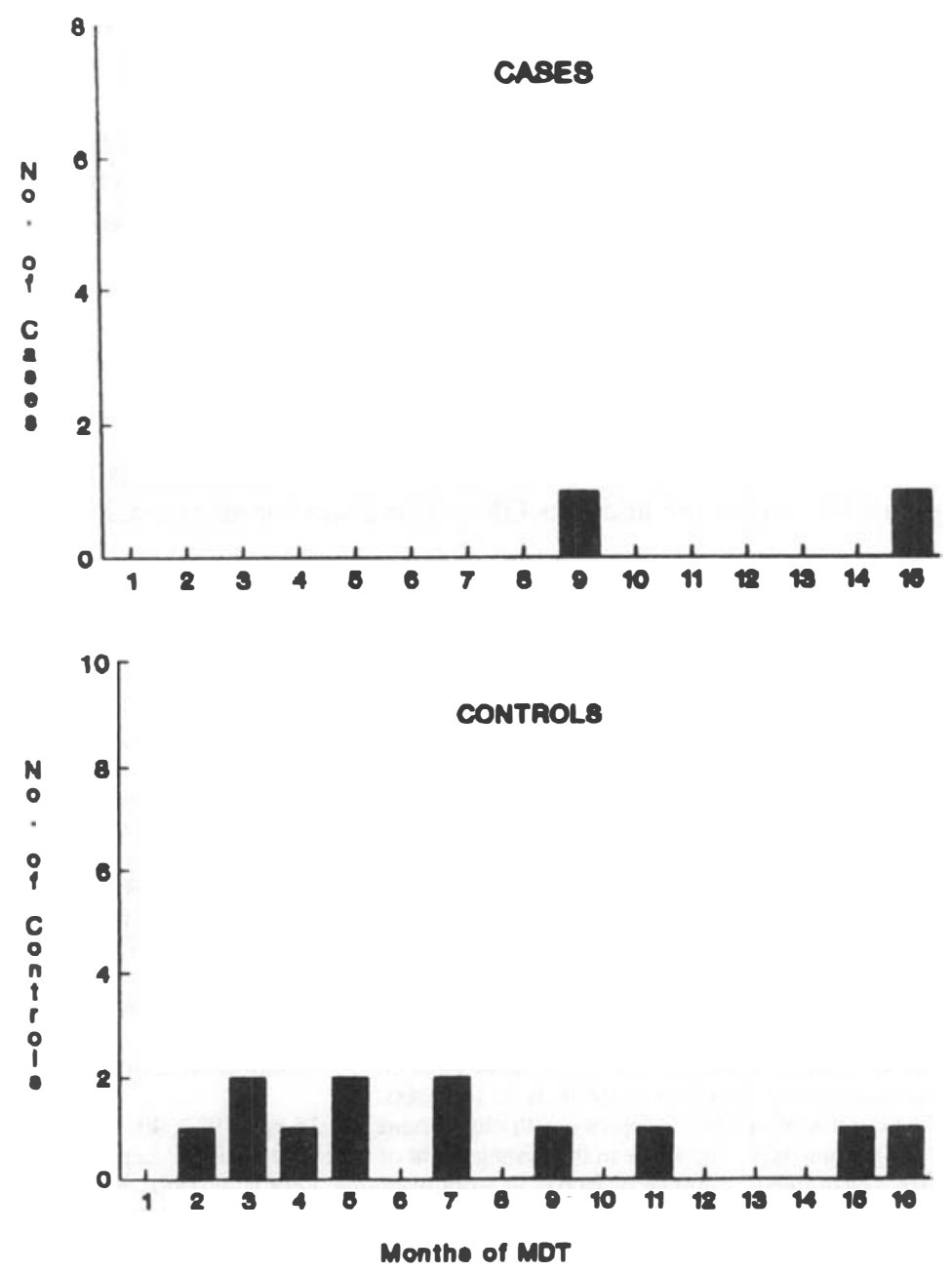

Figure 2. Time of occurrence of Type I reaction/neuritis in the test group and the control group. Note: only reactions involving nerves are shown. 
MB-MDT regimen may have helped in maintaining high tissue levels through the risk periods of therapy.

Earlier investigations did not find clofazimine to be useful in Type I reaction. This was probably because it was used as a therapeutic agent rather than prophylactic, and hence could not have achieved high tissue levels fast enough to prevent irretrievable nerve damage.

The percentage of Type I reaction/neuritis which occurred in our test group seem significantly less even when compared with rates published from other centres. The drop outs in our study were a confounding factor and it is difficult to estimate their significance. One interesting finding was the difference in this pattern of drop outs between the test group and the control group (Figure 1). Drop outs were more in the second year for the test group while the reverse was true for the control group. The time of occurrence of reactions were also different (Figure 2). It appears that ma jority of the reactive episodes took place within the first 6 months for the control group while the two episodes in the test group occurred after 8 months after 14 months. If occurrence of reaction is an important reason for dropout, then it would be tempting to suggest that clofazimine given as it was in this study merely postpones reactive episodes, thus explaining the later drop outs in the group.

However, there seems to be enough evidence to warrant a carefully controlled prospective field-based clinical trial to confirm the trends seen in this study. The search for a prophylactic agent is becoming more important as investigations to delineate high risk groups, using clinical and laboratory findings are advancing. ${ }^{27}$

\section{Acknowledgments}

We are grateful to Miss Nisha Kurian, Biostatistician for critical analysis and assistance. I would like to thank Mr Augustine and Mrs Glory Davidson for secretarial help.

\section{References}

1 Job CK, Nerve damage in leprosy. Int J Lepr, 1989; 57: 532-9.

2 Becx-Bleumink M, Berhe D. Mannetje WT. The Management of nerve damage in the Leprosy control services. Lepr Rev, 1990; 61: 1-11.

3 Groenen G, Janssens L, Kayembe T. Nollet E, Coussens L, Pattyn SR. Prospective study on the relationship between intensive bactericidal therapy and leprosy reaction. Int J Lepr, 1986; 54: 236-44.

${ }^{4}$ Boerrigter G, Ponnighaus JM, Fine PEM and Wilson RJ. Four year follow-up results of a WHO recommended multiple drug regimen in paucibacillary leprosy patients in Malawi. Int J Lepr, 1991; 59: 255-61.

5 Rose P, Waters MFR. Reversal reactions in Leprosy and their management. Lepr Rev, 1991; 62: 113-121.

6 WHO. Chemotherapy of leprosy for control programmes. WHO Tech Rep Series No. 675; 1982.

7 Hastings RC. Leprosy. Churchil Livingston. 1985.

8 Ramu G, Giridhar A. Treatment of steroid dependent cases of recurrent Lepra reactions with a combination of thalidomide and clofazimine. Ind J Lepr, 1970; 51: 487-504.

9 Karat ABA, Anbu Jeevaratnam, Karat S. Rao PS. Double-blind controlled clinical trial of clofazimine in reactive phases of lepromatous leprosy. Brit Med J, 1970; 1: 1: 198-200.

10 Pfaltzgraf RE. The control of neuritis in leprosy with clofazimine. Int J Lepr, 1972; 40: 392-398.

11 Ross WF. Does clofazimine have any value in the management of reversal reactions? Lepr Rev, 1980; 51: 92-3.

12 Impkamp FMJH. Clofazimine (Lamprene or B663) in lepra reactions. Lepr Rev, 1981; 52: 135-40.

13 Thirugnanam T, Rajan MA. Borderline reactions treated with clofazimine and corticosteroids. Ind J Lepr, 1985; 57: 164-71.

14 Arunthathi S, Jacob M and Chacko CJG. Borderline lepromatous leprosy masquerading as 'paucibacillary leprosy' - A Clinico Pathological Study. Part I Clinical Features. Abstract 17. XIV All India Bienniel Conference, Jabalpur, India 1986. 
15 Chacko CJG, Jacob M and Arunthathi S. Borderline lepromatous leprosy masquerading as 'paucibacillary leprosy' - A Clinico Pathological Study. Part II Pathological Features. Abstract 18. XIV All India Bienniel Conference, Jabalpur, India 1986.

16 Browne SG. B663 (Geigy) - further observations on its suspected anti-inflammatory action. Lepr Rev, 1966; 37: $141-145$.

17 Schulz EJ. Forty four months experience in the treatment of leprosy with clofazimine. (Lamprene (Geigy)) Lepr Rev, 1971; 42: 178-187.

18 Vischer WA. The experimental properties of G 30, 320 (B663)-a new anti-leprotic agent. Lepr Rev, 1969; 40: 107-110.

19 Waters MFR. G 30, 320 or B663- Lampren (Geigy). A working party held at the Royal Garden Hotel. London. September 1986. Lepr Rev, 1969; 40: 21-47.

20 Sarracent J, Finlay CM. In vivo effect of clofazimine in the lysosomal enzyme level and immune complex phagocytosis of mouse peritoneal macrophages. Int J Lepr, 1982; 52: 154-158.

21 Gatner EMS, Anderson R, Van Rensburg CE and Impkamp FMJH. The In vitro and in vivo effects of clofazimine on the motility of neutrophils and transformation of lymphocytes from normal individuals. Lepr Rev, 1982; 53: 85-90.

22 Zeis BM, Anderson R, Sullivan JFO. The effect of ten phenazine derivatives in comparison to clof azimine on the production of prostaglandin E2 by polymarphonuclear leucocytes. Lepr Rev, 1987; 58: 383-388.

23 Banerjee DK, Ellard GA, et al. Some observations on the pharmacology of clofazimine. Am J Trop Med Hyg, 1974; 23: (6): 1110-5.

${ }^{24}$ Mansfield RE. Tissue concentrations of clofazimine (B663) in man. Am J Trop Med Hyg, 1974; 23: 1116-9.

25 Desikan KV, Balakrishnan S. Tissue levels of clofazimine in a case of leprosy. Lepr Rev, 1976; 47: $107-113$.

${ }^{26}$ Balakrishnan S, Seshadri PS. Drug interactions - the influence of rifampicin and clofazimine on the urinary excretion of DDS. Lepr. India, 1981; 53: 17-22.

27 Roche PW, Theuvenet WJ, Britton WJ. Risk factors for Type I reactions in borderline leprosy patients. Lancet, 1991; 338: 654-57. 